To appear in Connection Science

Vol. 00, No. 00, Month 20XX, 1-15

\title{
Autopoiesis, Creativity and Dance
}

\author{
J. Mark Bishop ${ }^{\mathrm{a} *}$ and Mohammad M. Al-Rifaie ${ }^{\mathrm{b}}$ \\ a TCIDA, Goldsmiths, University of London, London, UK; ${ }^{b}$ Dept. Computing, Goldsmiths, \\ University of London, London, UK
}

(Received 00 Month 20XX; accepted 00 Month 20XX)

\begin{abstract}
For many years three key aspects of creative processes have been glossed over by theorists eager to avoid the mystery of consciousness and instead embrace an implicitly more formal, computational vision: autonomy, phenomenality and the temporally embedded and bounded nature of creative processes. In this paper we will discuss autopoiesis and creativity; an alternative metaphor which we suggest offers new insight into these long overlooked aspects of the creative processes in humans and the machine, and examine the metaphor in the context of dance choreography.
\end{abstract}

\section{Introduction}

"And how will you enquire Socrates, into that which you know not? What will you put forth as the subject of your enquiry? And if you find what you want, how will you ever know that this was the thing that you did not know?", (Plato, 'The Meno', circa 380bc).

Although, perhaps surprisingly, the term 'creativity' has a relatively youthful etymology - it was as recently as 1927 that Alfred North Whitehead first coined the term in his Gifford lectures at the University of Edinburgh, (later published as 'Process and Reality' [30]), a term now so ubiquitous, that its recent origin is obscured - people have been contemplating the process of creation for millennia: from Plato in 'The Meno' (ibid); through 19th century and early twentieth century theorists whose accounts reified its conscious, almost divine, nature (e.g. by Graham Wallas [29] who explicitly engaged with its lived, phenomenological component; for Wallas 'intimation' is the feeling a creative person gets when a solution is on its way and 'illumination' the point at which the creative idea bursts forth into conscious awareness); to the modern era where the computational zeitgeist has encouraged purely formal accounts, more amenable to mechanical instantiation and explanations.

In contrast, in this paper we resist the computational turn and instead argue for a lived, phenomenological account of creativity, predicated on a strong notion of the embedded, embodied mind and enactivism [28]. An account that takes seriously the idea that creative processes:

(1) have a conscious, phenomenal element - it feels like something 'to create' and 'to know';

\footnotetext{
${ }^{*}$ Corresponding author. Email: m.bishop@gold.ac.uk
} 


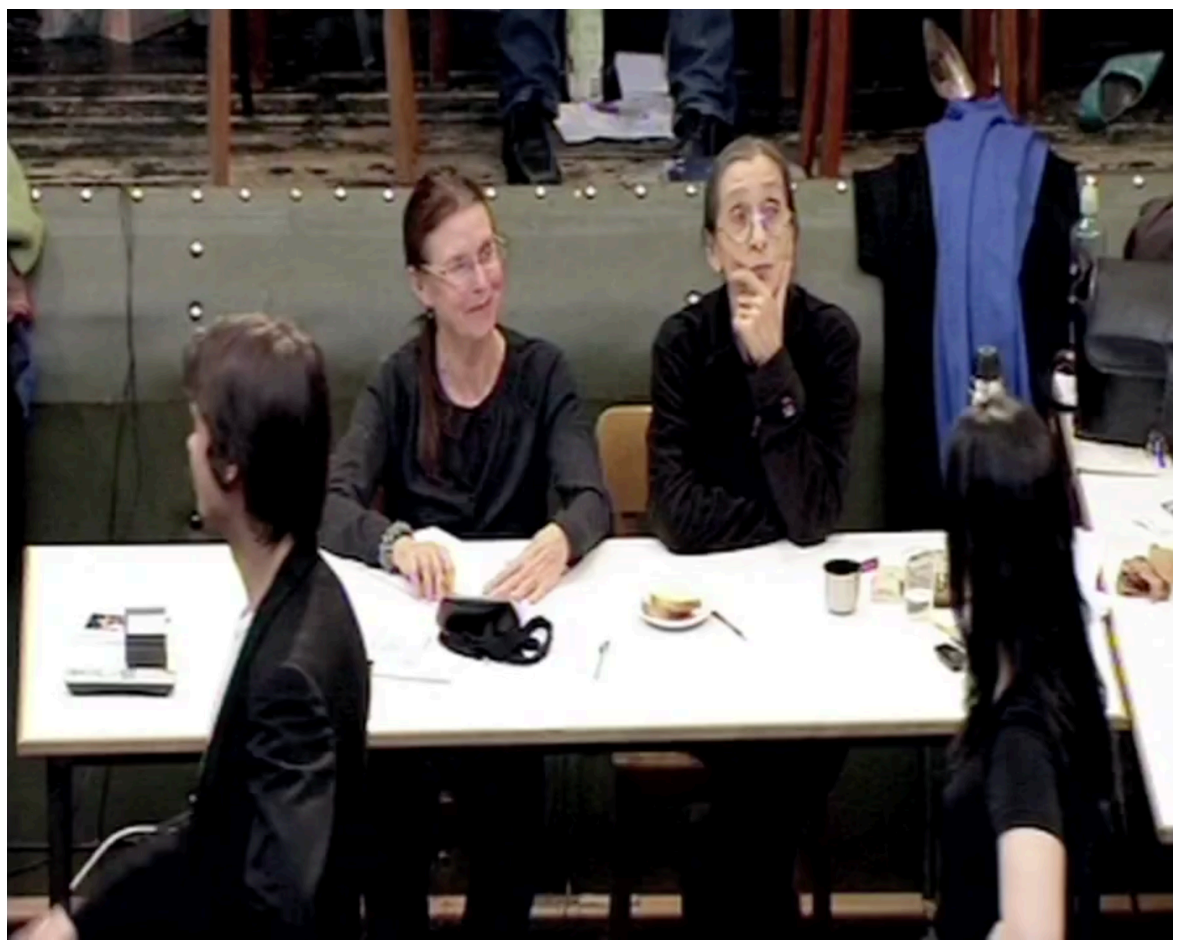

Figure 1. Pina Bausch watching her young dancers parade in a new production of Kontakthof.

(2) are temporarily bounded;

(3) abound with notions such as, "embodied flow" "being in the zone" etc. which typically entail an altered mode of 'being in the world' - neither fully subjective or objective: the potter at his wheel; the mathematician lost in her equations; the tennis player enmeshed in a long, hard rally.

In this context we wish to rehabilitate older notions of creativity (such as that from Wallas [ibid]) - which engage with the subjective (feeling of creation) and also invoke another state of being (neither fully objective of subjective) - in a new enactivist account delineated by Varela et al (ibid), in terms of Maurice Merleau-Ponty's "entre-deux":

"The world is inseparable from the subject, but a subject which is nothing but a project of the world; and the subject is inseparable from the world but a world which is nothing but a project of the subject".

In Figure (1) we see the iconic German dance choreographer, Pina Bausch, as she leads 40 teenagers, who have never heard of her or her work, into a new production of perhaps her most minimalist Tanztheater, Kontakthof. How, given the times that she has staged the piece since its inception 1978, did she succeed in bring-forth something new?

We believe that a clue to the answer may lie in the very processes Bausch used in re-staging Kontakthof. Her work with the 40 teenagers was not merely a re-staging of set choreography (which often means the dancer mimics, learns or copies, rather than interprets ${ }^{1}$ ), but a more organic improvisational process, specific to Bauschs own creative process of re-staging around pre-existing choreography, for which interpretation and learning of the movement gestures goes hand-in-hand.

\footnotetext{
${ }^{1}$ Although, of course, interpretation can be an emergent property of such action.
} 


\section{Creativity in movement and dance}

There are many ways to think about systems that choreograph movements that we socially conceive of as dance. This theoretical work ${ }^{2}$ is inspired by Alfred North Whitehead's process view of organisation ${ }^{3}[30]$, viewed though the transformational conceptual-lens of autopoietic theory (Maturana and Varela [19]); according to which we view a creative system as a clearly delineated and identifiable network of continuously operational component producing processes and concomitant elements, bounded as an autonomous entity within its own creative environment.

So construed, the autopoietic dancer can never be fully satisfied with her work, but continually re-engages a complex process of 'attention' (on her current movement context) and 'reconstitution' (of her body), as she creatively reflects and enacts her world.

The autopoietic dancer lives in a universe of meaning-distinctions - the totality of which constituting her dance-field - and her dance begins as creative processes are drawn to, and collectively attend, these distinction(s); from which, at successive instants, she chooses one element, the most 'interesting' gesture, to (re)interpret. In this manner the autopoietic dancer continuously reflects and refracts back into the world she has just brought forth, reinventing her universe in order that she may subsequently generate further new (re)interpretations.

As interpretations disappear with their appearance, they cannot be altered, but only give cause for the production of new movements, which are subject to the same mechanism. Thus, while there is a stimulating 'dance-field' with which to interact - and she continues to (re)interpret interesting and meaningful gestures - this autopoietic unity will continue intact. Conversely, as the dance-field becomes less stimulating, the meaningdistinctions become less interesting and the autopoietic unity more-likely to fade and ultimately dissolve; in the very moment of such movements coming into being, they already fade away and the dancer returns to reflect stillness again ${ }^{4}$.

\section{On 'meaning distinctions' and the 'dance-field'}

Central to the operation of the dancer's autopoietic unity is the identification of interesting meaning distinctions in the dance-field which, through her dance, she is able to

\footnotetext{
${ }^{2}$ This paper forms the left hand side of a diptych in which, herein, we offer autopoiesis as a new light under which to view creative processes in richly embodied movement and dance; a philosophical exegesis of the core generic concepts relating autopoiesis and creativity first discussed at AISB2016, Sheffield UK; cf. Bishop \& AlRifaie, Autopoiesis, creativity and Dance [8]. The original conceptual driver - relating swarm intelligence and autopoiesis - first emerged in work by Al-Rifaie and Bishop [on swarmic sketching] and subsequent discussions on computational art with Leymarie and Latham. Conversely, forming the right hand side of the diptych (and working alongside Frederic Leymarie and William Latham) we instantiate the autopoietic metaphor of creativity via a specific computational mechanism and successfully deploy this to improvise new computational sketches [3]. ${ }^{3}$ For Whitehead, all real objects may be better understood as a constructed series of events and processes. It is this core idea that Whitehead explains the seminal 'Process and Reality' [30], concluding that it is process, rather than substance, that should be taken as the most fundamental metaphysical constituent of the world, "That 'all things flow' is the first vague generalization which the unsystematized, barely analysed, intuition of men has produced. Without doubt, if we are to go back to that ultimate, integral experience, unwarped by the sophistications of theory, that experience whose elucidation is the final aim of philosophy, the flux of things is one ultimate generalization around which we must weave our philosophical system", (ibid. pp. 317).

${ }^{4}$.. in much the same way as Koskinen identifies that all business organisations eventually wither, dissolve away and ultimately die ".. decisions have to be imagined as events. In the very moment of their coming into being, they already fade away. Therefore, only little can be changed in business organizations. As decisions disappear with their appearance, they cannot be altered, but only give cause for the production of new decisions, which are subject to the same mechanism. And this is the reason why business organizations step by step wither and die", (K.U. Koskinen, 'Why do Business Organizations die? Social Autopoietic Perspective').
} 
(re)interpret.

\subsection{Relationship to the Stanislavsky system}

Under the gaze of the 'autopoietic dancer', we conceive of her dance-field as comprised of 'meaning distinctions' emerging from the dancer's umwelt ${ }^{5}$ of elements and gestures an open door; a movement of the head; the tension in a finger or arm; an inviting smile; a light; a memory invoked; a shadow etc. - in this manner 'meaning distinctions' of most interest to the dancer, neither fully subjective or objective in character, are brought-forth through her choreographic interaction with the environment.

The totality of such 'atomic' meaning distinctions - delineating her sensorium, or field, of movement embedded in sight, sound, touch and personal lived history - comprise the artist's dance-field. By modulating the distinctions she is drawn to attend, as she creatively interacts with and explores her environment, the autopoietic dancer adapts what she construes as [artistically] 'meaningful' in her own historical dialogue.

Furthermore, by analogy with what one scholar of Stanislavsky calls the 'attention field' [10], the 'dance-field', so defined, has a strong resonance with core ideas from Stanislavsky; as Ysabel Claire (ibid) observes:

"The arrangement of information in Stanislavskys inner world, then, is orientational, or adpositional, because it is orientated in positional relationships to a source in a notional three-dimensional space. In an adpositional model relationship is key. Therefore, in this perceptual model, the circumstances of a persons life at any given moment (on-line) are located perceptually in space, adpositionally: around the body. At any moment, we are experiencing a particular configuration of available thoughts, memories, and feelings: I have called this an attention-field. Patterns and consistencies within this field are apparent to the observer as that information is leaked both verbally and non-verbally."

\subsection{Relationship to Dynamic Field Theory}

In modern cognitive science Dynamic Field Theory outlines a important shift towards a new and intentionally integrated theory of cognition. Thus, in their introduction to the work of the DFT Research Group, as they move toward a unified theory of cognitive dynamics, Spencer and Schoner suggest:

" DFT provides an embodied account, that is, neural processes are grounded in sensory and motor processes that are anchored on a body situated in a physical environment .. we are pursuing a general theory that spans perception, action, and cognition .. carrying forward a set of common principles as we move from lower- to higher-level cognition", [25].

Furthermore, in [10] Clare grounds the cognitive dynamics of 'Dynamic Field theory' to the actor via the notion of 'attention-field' as follows:

"The Group outlines different types of 'attention-fields' - spatial attention-fields, scene attention-fields, feature attention-fields, transformation attention-fields, contrast fields retinal fields within which attentional foregrounding, hills and peaks of activation, and sequential transitions occur. Although these are short-term attention-fields, they can be related to

\footnotetext{
${ }^{5}$ As Clare[10] observes, "Jacob von Uexkull labelled perception of the world, experienced by and through the capacity of species-specific bodies, the umwelt: literally surround-world. That is to say it is inherently embodied because it is biologically limited by the sensory apparatus of the physical body". Stanislavsky, developing a system of practice for the actor, that was in opposition to purely representational modes of melodrama, offered one of the first modes of training that, "... implicitly addresses this very subject, teaching the student to contextualize their individual umwelt within a wider framework of the human umwelt: the spatial adpositional umwelt. This both frames the acting process and opens the students awareness to what is humanly possible", (ibid).
} 
the constructed attention-field of the actor, a long-term, artificially sustained field with a complex contextual function .. Other relevant aspects of DFT include descriptions of working memory fields as feature, spatial, or scene .. In a chapter on Integrating perception-action with cognition (pp. 197-226), Schneegans, Spencer, and Schoner address the attention-field and working memory patterns of individuals in relation to objects in the real world - it would be extremely useful to extend this to imagined objects and the conceptual world within which actors function and construct the lives of their parts over time."

\section{On autopoiesis and allopoiesis}

\subsection{Autopoiesis or self-creation}

Maturana and Varela's original definition of autopoiesis is found in [19]:

"An autopoietic machine is a machine organized (defined as a unity) as a network of processes of production (transformation and destruction) of components which: (i) through their interactions and transformations continuously regenerate and realize the network of processes (relations) that produced them; and (ii) constitute it (the machine) as a concrete unity in space in which they (the components) exist by specifying the topological domain of its realization as such a network", (p. 78).

Thus, the boundary of an autopoietic system is determined circularly by the production of its constituent elements; in this way the organisation of, say, a cell is both 'circular' and autopoietic because the components that specify the cell are the same components that the organisation of the cell secures and maintains. It is this circularity that maintains the cell as a living entity. It is in this sense that an autopoietic system can be considered as a special type of homeostatic system, where the variable to be maintained and controlled is the organisation and behaviour of the system. For Francisco Varela, autopoiesis is both necessary and sufficient to characterise the organisation of living, autonomous systems.

In addition to maintaining the conditions for its own continued existence, an autopoietic system may, in addition, generate allopoietic system(s) as output(s).

\subsection{Allopoiesis}

In contrast to autopoiesis, the operation of an allopoietic system is given in terms of the concatenation of processes. Such processes are not the processes that specify the components of the system itself, as a unity; instead the components are produced by other processes that are independent of the organisation of the system. Because the components that make up an allopoietic system's existence are contingent upon other systems, an allopoietic system is never 'fully autonomous'. Some examples of allopoietic systems are: cars, trains, robots etc.

Furthermore, because an allopoietic system is always contingent on the output of other systems for it existence, its teleology and meaning will always reside in the observers world, never in its own - the systems - world.

\subsection{On the autopoietic status of systems}

To determine whether a system is or is not autopoietic in its organization, Varela et al. [27] have developed six key points or criteria that should be applied to the system; Koskinen [15] restates these criteria as follows: 
(1) Determine, through interactions, if the unity has identifiable boundaries. If the boundaries can be determined, proceed to 2 . If not, the entity is indescribable and we can say nothing.

(2) Determine if there are constitutive elements of the unity, that is, components of the unity. If these components can be described, proceed to 3 . If not, the unity is an un-analyzable whole and therefore not an autopoietic system.

(3) Determine if the unity is a mechanistic system, that is, if the component properties are capable of satisfying certain relations that determine the unity, the interactions, and transformations of these components. If this is the case, proceed to 4 . If not, the unity is not an autopoietic system.

(4) Determine if the components that constitute the boundaries of the unity constitute these boundaries through preferential neighbourhood relations and interactions between themselves, as determined by their properties in the space of their interactions. If this is not the case, you do not have an autopoietic unity because you are determining its boundaries, not the unity itself. If 4 is the case, however, proceed to 5.

(5) Determine if the components of the boundaries of the unity are produced by the interactions of the components of the unity, either by transformation of previously produced components, or by transformations and/ or coupling of non-component elements that enter the unity through its boundaries. If not, you do not have an autopoietic unity; if yes, proceed to 6 .

(6) If all the other components of the unity are also produced by the interactions of its components as in 5, and if those which are not produced by the interactions of other components participate as necessary permanent constitutive components in the production of other components, you have an autopoietic unity in the space in which its components exist. If this is not the case and there are components in the unity not produced by components of the unity as in 5 , or if there are components of the unity which do not participate in the production of other components, you do not have an autopoietic unity.

Thus, the successful application of the above six-point taxonomy is sufficient to determine if a system is autopoietically organized (or not).

\section{Luhmann: autopoeisis and social systems}

In formulating his law of requisite variety William Ross Ashby [4] observed that to survive in a complex environment while maintaining internal stability and structure, a system must be able to generate an appropriate gamut of responses to an ever changing environment. In contrast, General Systems Theory, as formulated by Ludwig von Bertalanffy [6], assumes an open systems model ${ }^{6}$, viewing complex systems in terms of the difference between 'the system and its environment'; contra a closed system model ${ }^{7}$ and mereological distinctions between, say, the physical instantiation of 'whole and parts'.

Influenced by General Systems Theory, the core element of Niklas Luhmann's 'system theoretic' view of social systems is communication: social systems are systems of communication and society is the most encompassing social system. In Luhmann's view [17] a social system is defined by the boundary between itself and its environment, which is considered an infinitely complex ('chaotic') exterior. Thus, relative to the exterior, the

\footnotetext{
${ }^{6}$ An open system exchanges material, energy, people, capital, information etc. with its environment.

${ }^{7} \mathrm{~A}$ closed system does not allow transfers in or out of the system.
} 
interior of the social system is a space of reduced complexity: communication within a social system operates by selecting only a limited element of all the information available outside the system. In this way Luhmann's concept of communication inherently entails a "reduction of complexity", whereby the criteria according to which information is selected and processed is meaning. Thus social systems are operationally closed because, while they use and rely on resources from their environment, those resources do not become an integral part of the systems' operation.

Thus for Luhmann, social systems operate by processing meaning and furthermore, each system has a distinctive identity; a unity, that is constantly reproduced in its communication and depends on what is considered meaningful (and what is not) for that system. If the system fails to maintain this identity, it dies, it ceases to exist and it dissolves back into the wider environmental ether whence it came.

Luhmann conceived this process of continuous reproduction from elements previously filtered from an over-complex environment as autopoiesis ${ }^{8}$.

\subsection{Social cognition and autopoietic enactivism}

Furthermore, by demonstrating how consciousness and subjective experience are related to the brain and body of an organism in enactivist theory, Evan Thompson [26] binds the notion of autopoiesis to consciousness - not just cognition.

"... our environment is one which we selectively create through our capacities to interact with the world. Organisms do not passively receive information from their environments, which they then translate into internal representations. Natural cognitive systems .. participate in the generation of meaning ... by engaging in transformational, and not merely informational, interactions; they enact a world."

In this light, and following Luhmann, Hanne De Jaegher and Ezequiel Di Paolo [13] have extended the enactive concept of 'sense-making' [26] into the cultural domain, whereby De Jaegher and Di Paolo argue that the interaction process itself can take on a form of autonomy (operationally [autopoietically] defined). This allows us to consider autopoiesis in creativity as the generation of meaning and its transformation through individuals interacting [within a dance-field].

\section{6. 'Creativity' as an autopoietic process}

\subsection{Historical}

The resonance of art with autpoiesis has been explored by several thinkers, most notably Luhmann who in his theory of social systems [18] famously put forward a 'theory of art' as "a particular system of communication", i.e. ".. the function of art can be traced to problems of meaningful communication" [16]. For Luhmann, the domain of art is to be viewed as an operationally closed and self-referential communicative system, an autopoietic system; radically suggesting that it is ".. from the autopoiesis of art which

\footnotetext{
${ }^{8} \mathrm{NB}$. Both Varela and Maturana have forcefully argued against this appropriation of the term autopoiesis; in Maturana and Varela's conception, people cannot be proper elements of a social system's renewal because (a) in describing social systems as operationally closed networks of communications, Luhmann ignores the fact that communications presuppose human communicators [21] and (b) people are not (re)produced as an integral and core part of a social system's renewal processes [22].
} 
works of art will be created". This led Rampley, in his review [24], to suggest that the ".. key question Luhmann addresses [in his conception of art and autopoiesis] is how art differentiates itself from other systems".

A traditional, representation-heavy, view of the artist as an open-system, fundamentally posits the artist's activities as contingent on external influences; the artist responds creatively to demands from a pre-given, objective environment by building and creatively processing appropriate internal representations. In this view, through his art, the artist builds representations of a pre-given reality - universal, objective, and transferable - and it is his role, as artist, to transform these representations in novel, interesting and creative ways.

The contrary, autopoietic perspective reflects that creativity is autonomous and operationally closed ${ }^{9}$. In addition, autopoietic creative systems stand 'structurally coupled' with their medium; fundamentally embedded in a dynamic of changes, exercised via appropriate sense-action coupling. This continuous dynamic can be considered a rudimentary form of creative knowledge.

Emerging from a General System Theory perspective, the exploration of autopoiesis in the context of 'creativity studies' was first outlined by Gornev in 1997 [12] who first set out to construct a theory of human creativity on the foundation of autopoietic systems theory (AST), whereby:

"creativity is seen as an activity recurrently reproduced by couplings of specific states of moderate emotional arousal with transitional environments, i.e. soft social structures in which the world is permitted to be both subjective and objective; the archetype of these creative couplings can be found in the earliest perfect environment formed by the symbiotic infant/mother relationship".

In contrast in 2010 Takashi Iba [14] defined "Creative Systems Theory" in order to view creative processes ${ }^{10}$ in an alternative way, ".. focusing the process itself without the reference to psychic or social aspects". In his work Iba postulated creative processes to be "autopoietic systems whose elements are 'discoveries' emerged by a synthesis of three selections: idea, association, and consequence".

However, by merely defining that "creativity is an autopoietic system whose element is discovery", Iba's work, like Gornev's first tentative explorations thirteen years earlier, remains floating very much at a conceptual level; it offers little insight into how 'creative process' at the personal, 'psychic', artistic level could ever actually be cached out; indeed, as he stated in the paper (ibid), this was never his project.

\subsection{Our view}

Conversely, and in an analogous manner to Luhmann's conception of information processing, we view creativity as entailing a reduction in complexity of meaning in the environment; with the system operationally closed because, while its creativity uses and relies upon resources from its environment, these resources do not become part of the underlying systems' operation.

Viewed under this conception, a creative system (a) processes meaning and (b) maintains a distinctive identity; a unity that is repeatedly reproduced in its operation, con-

\footnotetext{
${ }^{9}$ It is operationally close in the sense that there are sufficient processes within it to maintain the unity of creation and that, while they use (and rely upon) resources from their environment, those resources do not themselves become an integral core element of the creative systems' operation.

${ }^{10}$ Iba defines that a creative process consists of "a sequence of discoveries, which include problem finding, problem solving, observation, hypothesis formation, method selection, practice, and interpretation", (ibid).
} 
tingent upon what is considered meaningful (or not) for the system. If the environmental conditions are such that, over time, the creative system can no longer maintain this identity, then its investigations will simply dissolve away to void.

In this way creativity is a constructive process; it inherently reflects an individually constructed artistic reality. Furthermore, because autopoietic creativity emerges from the observation of distinctions and not of things, its operation is fundamentally contingent on its own history, and in this way is ever-sensitive to its own historical context.

In summary, and in contrast to the classical view of creative processes building (reflecting on and transforming) representations of a pre-given, out-there, world, an autopoietic view of creativity is based on the simultaneous knowledge processes of sensing and memory. In this context memory ${ }^{11}$ entails that:

- the unity has access to its existing knowledge;

- previous, accumulated, knowledge modulates the the unity's ongoing structures and operations;

- the unity's cognitive structures and operation affect its acquisition of new data from the environment and its creation of new internal knowledge structures.

Furthermore, we observe that by conceptualising creative processes within an autopoietic framework, we must conclude that creativity is never a directly transferable skill or knowledge ${ }^{12}$.

\section{Autopoiesis, creativity and dance}

In our work we examine a dancer, typically working with a rehearsal director, a choreographer, who guides the dancer's movements. We consider the space defined by the dancer's state-of-mind, the dancer's movements and teacher's movements as the dance-field ${ }^{13}$. The continual creative processes of attention and reconstitution (movement) mechanisms that act in this field are detailed in the accompanying paper (in the context of 'the Autopoietic Artist' - a 'weakly creative' computational drawing system) [3].

We see in Figure (2) Jo, one of the rehearsal Directors of this production of Kontakthof, working with one of the students, and draw the reader's attention to three observations from the scene:

(1) From her expression it is apparent that the dancer is both deeply engaged and acutely feeling the creative process.

(2) There appears to be a diminution of the dancer's subjective self, as her concentration and bodily-control bring-forth a deeply engaged coupling between her actions, the choreographer's intent and her environment.

(3) The precariousness and temporal boundedness of the creative act. Eventually in the rehearsal, we see the dancer's coupling dissipate as she returns to her normal, subjective, self-critical state: a 'being in time'.

${ }^{11}$ A self-referential process which facilitates access to, and learning from, previous experiences and knowledge [15].

${ }^{12} \mathrm{Cf}$. Koskinen on 'autopoietic knowledge systems in project-based companies' [ibid]

${ }^{13}$ Mathematically imagined represented as a complex manifold. 


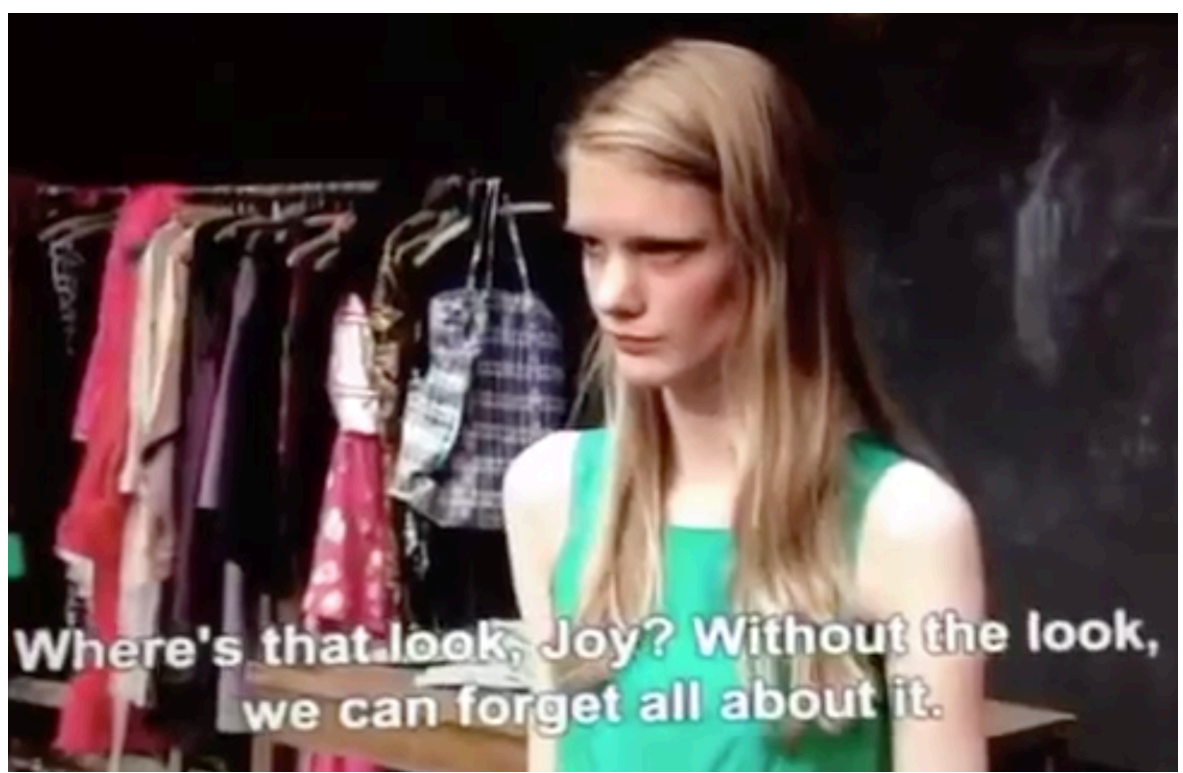

Figure 2. Image of young dancer in Kontakthof as she listens to feedback from Jo, one the rehearsal Directors.

\section{The autopoietic dancer as a 'strongly' creative system}

We view the creative, guided-improvisations of the 'autopoietic' dancer as being primarily directed by two functionally distinct processes: (i) a process of attention whereby the dancers 'cognitive resources' are drawn to (potentially multiple) elements of meaningdistinction in the dance-field that are in some sense important to the dancer (in [3] we suggest this could be computationally realised by stochastic diffusion processes [7]; see Appendix (A)) and (ii) a process of interpretation whereby a movement is (re) interpreted by the dancer in her performance (a process which in [3] we suggest could be computationally realised by a 'particle swarm'; see Appendix (B)). Elements of the dance-field that are most meaningful/important to the dancer (at this particular instant in time) will attract the most cognitive resources, resulting in these elements to be attended to next by the (re)interpretation processes controlling the dancer's movement(s).

NB. It is a natural consequence of considering the dancer's control of her creative movements as an autopoietic process defined in this way, that a skilled dancer/performer will find some aspects of movement relatively simple (less interesting/meaningful) and hence not deploy so much cognitive resources to their (re)interpretation as a dancer relatively new to the movement; in this way the skilled dancer is thus free to redeploy resources in more meaningful areas of performance, perhaps focussing on perfecting the technicalities of a particularly difficult movement, or perhaps focussing on synthesising her movements as a whole etc.

In this manner the 'autopoietic' dancer is thus continually engaged in a process of sensing her environment (the dance-field) and reconstituting it (by iteratively first choosing a gesture of meaning and (re)interpreting it); hence Varela et al's criteria [27] for an autopoietic entity are appropriately instantiated in the cognitive processes of the 'autopoietic' dancer acting in the space in which her creative unity exists.

Over time, with her 'interest' drawn to areas rich in meaning (peculiar to her), the autopoietic dancer, so construed, iteratively reinterprets meaningful-distinctions (gestures) 


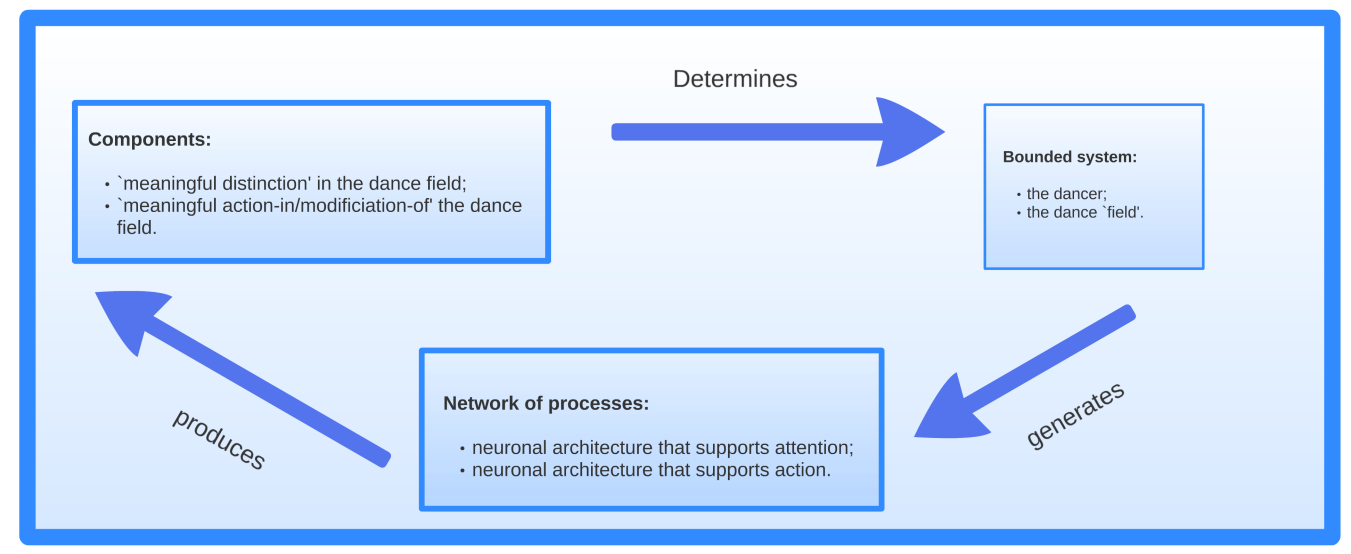

Figure 3. Autopoiesis in creativity and dance.

in her current dance-field, so offering a very personal reinterpretation of the structure of the work. Over time though, inevitably less of the dance-field will continue to offer up meaningful-distinctions, at which point the dancer's attention becomes gradually less focussed as her creative process stultify and eventually cease; reifying the movements' 'death' and returning the dancer to silence. Thus, following Luhmann's conception of information processing, we view the working autopoietic dancer as inevitably entailing a reduction in complexity, ravenously consuming 'meaning-distinctions' within her environment (the dance-field) until none remain and movement ends ..

In this light (see Figure (3) the autopoietic model we suggest offers a new account of creativity in terms of an operationally closed, casual circularity between three core groups of elements:

(a) The creative-actor as a bounded system consisting of:

- the actor [dancer];

- an 'attention-field' [dance-field] comprised of a multitude of potential 'meaningfuldistinctions'.

.. which generates ..

\section{(b) A network of processes:}

- neural processes that support attention;

- neural processes that support action.

.. which produces ..

(c) Components:

- 'meaningful distinctions' in the attention-field [dance-field];

- 'meaningful actions' in (and hence modification of) the attention-field [dance-field].

.. which [cyclically] update and together co-determine the bounded system ..

And we suggest that it is this - the dancer and her environment as a bounded system, an autopoietic unity - that precariously brings forth the phenomenology of her movement, alongside its inevitable dissipation .. 


\section{Conclusion}

In conclusion, in the context of Al-Rifaie and Bishop's 'weak' and 'strong' taxonomy of [computational] creativity [2], we suggest autopoiesis offers a new conception of 'strong' creativity' in movement and dance. This new autopoietic, enactive conception offers insights into (a) the phenonenality of the creative process - why it feels like something to create; (b) the altered state of the creative process - in this context Merleau-Ponty's 'entre-deux' conceptualises the state as being neither fully objective of subjective and (c) the time-bounded period of creativity as the autopoietic creative processes inevitably decays back to void. Furthermore, and in contrast to the computational autopoietic artist [3], because the dancer's biologically 'strongly embodied' [31] cognitive processes select areas of meaning distinction that are, in her current context, paradigmatically meaningful to her, the autopoietic dancer - richly embodied in her environment, the dance-field constitutes a fully autonomous strongly creative system.

\section{References}

[1] al-Rifaie, M.M., Bishop, J.M., (2013), Stochastic Diffusion Search Review, Journal of Behavioural Robotics: 4(3), pp. 155-173.

[2] Al-Rifaie, M.M. \& Bishop, J.M., (2015), Weak and Strong Computational Creativity, in Besold, TR, Schorlemmer M \& Smaill A, (Eds) (2015), Computational Creativity Research: Towards Creative Machines, 37-51, Springer.

[3] Al-Rifaie, M.M., Leymarie, F., Latham, W. and Bishop, J.M., (2016), Swarmic Autopoiesis and Computational Creativity, (in press, Connection Science forthcoming).

[4] Ashby, W. R. (1956). An Introduction to Cybernetics. London: Chapman and Hall.

[5] Barretto, F. P. and Venturelli, S. (2015). Zer0: an emergent and autopoietic multiagent system for novelty creation in game art through gesture interaction, 6th International Conference on Applied Human Factors and Ergonomics (AHFE 2015) and the Affiliated Conferences, AHFE 2015, published in Procedia Manufacturing: 3, pp. 850-857.

[6] Bertalanffy, L. von, (1968). General System theory: Foundations, Development, Applications, New York: George Braziller, revised edition 1976: ISBN 0-8076-0453-4

[7] Bishop, J.M., (1989), Stochastic Searching Networks, Proceedings of the First IEE International Conference on Artificial Neural Networks, pp. 329-331, (Oct 16-18, 1989), London, UK.

[8] Bishop, J.M. \& Al-Rifaie, (2016), Autopoiesis, Creativity and Dance, Proc. AISB 2016: 3rd Symposium on Embodied Cognition, Acting and Performance, Sheffield, UK.

[9] , Bratton, D. \& Kennedy, J., (2007), Defining a standard for particle swarm optimization, Proc of the Swarm Intelligence Symposium, pp. 120-127, IEEE Honolulu, Hawaii, USA.

[10] Clare, Y. (2016), Stanislavskys System as an Enactive Guide to Embodied Cognition: A Framework for Comparisons, Proc. AISB 2016: 3rd Symposium on Embodied Cognition, Acting and Performance, Sheffield, UK, (in press; forthcoming Connection Science). 
[11] Shi, Y. \& Eberhart, R.C., (1998), A modified particle swarm optimizer, Proceedings of the IEEE International Conference on Evolutionary Computation, pp. 69-73, IEEE Press, Piscataway, NJ.

[12] Gornev, G.P. (1997). The creativity question in the perspective of autopoietic systems theory, Kybernetes: 26(6/7), pp.738-750.

[13] De Jaegher, H. \& Di Paolo, E. (2007). Participatory Sense-Making: An enactive approach to social cognition. Phenomenology and the Cognitive Sciences, 6(4), 485507.

[14] Iba, T. (2010). An Autopoietic Systems Theory for Creativity. Proc. COINs2009: Collaborative Innovation Networks Conference published in, Procedia Social and Behavioral Sciences: 2, pp. 66106625.

[15] Koskinen, K.U., (2010). Autopoietic Knowledge Systems in Project-Based Companies, Palgrave Macmillan, UK.

[16] Luhmann, N. (1995). Social Systems. Stanford: Stanford University Press.

[17] Luhmann, N. (1995). Gesellschaftsstruktur und Semantik 4: Studien zur Wissenssoziologie der modernen Gesellschaft (Structure of Society and Semantic 4: Studies on Knowledge-Sociology of Modern Society). Frankfurt am Main: Suhrkamp.

[18] Luhmann, N. (1996). Die Kunst der Gesellschaft. Frankfurt a. M.: Suhrkamp.

[19] Maturana, H. and F. Varela, (1973). De Mquinas y Seres Vivos: Una teora de la organizacon biolgica. Santiago de Chile: Editorial Universitaria. (Reprinted in English in Maturana, H. and F. Varela, (1980)).

[20] Maturana, H. and F. Varela, (1980). Autopoiesis and Cognition: The Realization of the Living. Boston: D. Reidel.

[21] Maturana, H., \& Poerkson, B. (2004). From Being to Doing: The Origins of the Biology of Cognition. Carl Auer International. pp. 105108. ISBN 3896704486.

[22] Maula, M. (2006). Organizations as Learning Systems: Living Composition" as an Enabling Infrastructure (Advanced Series in Management), Elsevier.

[23] Moglich, M, Maschwitz, U, Holldobler, B (1974) Science 186(4168):1046-1047

[24] (2009), Rampley, M. Art as a Social System: The Sociological Aesthetics of Niklas Luhmann, Telos: 148, pp. 111-140.

[25] Schoner, G., Spencer, J., and the DFT Research Group. (2015). Dynamic Thinking: A Primer on Dynamic Field Theory. Oxford: Oxford University Press.

[26] Thompson, E., (2007), Mind in Life. Harvard University Press, Cambridge, Massachusetts, USA.

[27] Varela, F. J., Maturana, H. R., and Uribe, R. (1974). Autopoiesis: The Organization of Living Systems, Its Characterization and a Model. Biosystems, 5(4), pp. 187-96.

[28] Varela, F.J., Thompson, E. \& Rosch, E., (1991), The Embodied Mind: Cognitive Science and Human Experience. The MIT Press.

[29] Wallas, G. (1926). Art of Thought, (reprinted by Solis Press 2014).

[30] Whitehead, A.N., (1929), Process and Reality, New York: Macmillan.

[31] Ziemke, T. (2001). Disentangling Notions of Embodiment. Workshop on Developmental Embodied Cognition, Edinburgh, UK, July 2001. 


\section{Appendix A. Stochastic Diffusion Search}

This section introduces Stochastic Diffusion Search (SDS) [7] - a swarm intelligence algorithm - whose performance is based on simple interaction of agents. This algorithm is inspired by one species of ants, Leptothorax acervorum, where a 'tandem calling' mechanism (one-to-one communication) is used, the forager ant that finds the food location recruits a single ant upon its return to the nest; therefore the location of the food is physically publicised [23].

SDS is an efficient Swarm Intelligence global-search meta-heuristic [1], which we deploy herein to search for 'meaningful distinctions' in the dance-field. The principles of SDS can be most easily illustrated via analogy. Consider, 'The Bar Game':

A group of delegates attend a conference on computing and movement in Thessaloniki and want to spend their evenings at the best bar in town; Thessaloniki, for those who are new to its charms, has a huge number of great bars and each delegate will have their own taste defining what constitutes a good bar and a good night out.

Initially, each delegate adopts a random hypothesis of the best bar in town and visits that bar that night.

At the end of the evening each delegate merely needs to decide if they had a good evening or not (a stochastic decision informed on a subjective assessment of the bar and its clientele). I.e. Unless the bar is deemed 'perfect' by the delegate, there is a non-zero probability that, over time, even a good bar may result in a bad evening; nonetheless, across the population - ceteris paribus - delegates are likely to keep returning to a 'good' bar ..

The next morning each delegate who didn't like the bar they visited, asks a randomly selected co-delegate, if they had a good time the previous evening; if they did they simply adopt their fellow delegate's hypothesis, otherwise they simply reselect a new 'best-bar' hypothesis at random.

It can be shown that over a relatively short period of time a stochastic diffusion process (such as this) will converge, and a stable population of delegates will assemble on the best bar in town ..

More formally, the SDS algorithm commences a search or optimisation by initialising its population and then iterating through two phases (see Algorithm 1)

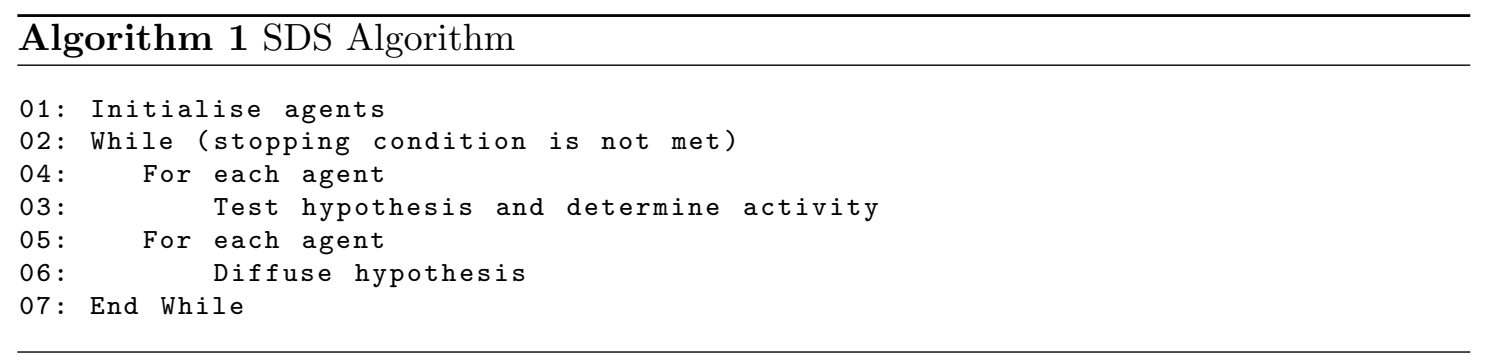

In the test phase of each iteration, SDS checks whether the agent hypothesis is successful or not by performing a hypothesis evaluation which returns a boolean value. In the diffusion phase, contingent on the precise recruitment strategy employed, successful hypotheses diffuse across the population and in this way information on potentially good solutions spreads throughout the entire population of agents. 


\section{Appendix B. Particle Swarm Optimisation}

A PSO is a swarm intelligence optimisation process, whose broad principles of operation we can illustrate with the following simple analogy:

Imagine that one dips a finger in a jar of honey and uses that honeyed-finger to trace a line in the air in the presence of a swarm of bees. Fairly soon the bees will begin to buzz around the honeyed finger tip. By using this swarm we can generate a new series of points (defining a new line) simply by noting the centroid of this swarm at successive instants in time.

More formally, a swarm in Particle Swarm Optimisation (PSO) algorithm comprises of a number of particles and each particle represents a point in a multi-dimensional problem space. Particles in the swarm explore the problem space searching for the optimal position, which is defined by a fitness function.

Each particle has a position $x$, a velocity $v$, and a memory, $p$, containing the best position found so far during the course of the optimisation, and this is called the personal best (pbest). $p$ can also be thought of as a particle 'informer'. Particles participate in a social information sharing network. Each particle is informed by its neighbours within this network, and in particular, the best position so far found in the neighbourhood, is termed the neighbourhood best. The position of each particle is dependent on the particle's own experience and those of its neighbours.

The standard PSO algorithm defines the position of each particle by adding a velocity to the current position. Here is the equation for updating the velocity of each particle:

$$
\begin{gathered}
v_{i d}^{t}=w v_{i d}^{t-1}+c_{1} r_{1}\left(p_{i d}-x_{i d}^{t-1}\right)+c_{2} r_{2}\left(g_{i d}-x_{i d}^{t-1}\right) \\
x_{i d}^{t}=v_{i d}^{t}+x_{i d}^{t-1}
\end{gathered}
$$

where $w$ is the inertia weight whose optimal value is problem dependent [11]; $\vec{v}_{i d}^{t-1}$ is the velocity component of particle $i$ in dimension $d$ at time step $t-1 ; c_{1,2}$ are the learning factors (also referred to as acceleration constants) for personal best and neighbourhood best respectively (they are constant); $r_{1,2}$ are random numbers adding stochasticity to the algorithm and they are drawn from a uniform distribution on the unit interval $U(0,1) ; p_{i d}$ is the personal best position of particle $x_{i}$ in dimension $d$; and $g_{i d}$ is the neighbourhood best. Therefore, PSO optimisation is based on particles' individual experience and their social interaction with other particles. After position and velocity updates, the positions of the particles are evaluated and the memories $p$ are updated, if a better position has been found. 